MACHINE FOR GRINDING BANDS ON GOBLETs. | the engine, or even less frequently, and a disturbing element effect is correspondingly great, and the wheel or its support The engraving shows a very simple and effective device will have been introduced which will strain the wheel later- must yield.

for grinding bands on the surfaces of goblets, wineglasses, ally, and which, together with centrifugal force, will effect No rotating machines are more subject to burstand other glass vessels of circular fo:m. It will be under- molecular changes in the structure of the iron, and the re- ing than grindstones, and generally no rotating bodies of stood by a glance at the illustration without a great deal of sult will be that if the wheel is not immediately broken it equal weight are mounted upon such small shafts or on such explanation. The larger end of the goblet is carried by a finally bicomes weakened, so that it will yielu to the forces weak supports. The suspended ones are especially liable to slightly conical chuck revolving on the lathe mandrel. that tend to destroy it. The bottom of the goblet is supported by a tail spindle Any wheel whose axis is swung in a plane at rigbt angles generally far too weak. pressed outward hy a spiral spring. A rod, supported by two posts, carries three or more arms having mortises in their free ends for receiving grinding pencils of copper or other suitable metal which are pressed on the glass by the weight of the arms. The pen cils are supplied with emery and water or other abrading material, and as the goblet revolves circumferential lines are very quickly formed on the rlass. The dionce fo the lines apart The ditance of the lines apart is regulated by moving the ars and fix ing them in position on the pivotal rod by means of mova

This machine was recently patented by Mr. J. B. Higbee, of Pittsburg, Pa.

A Botanist in the Field.

It is announced that the very capable field botanist, Mr. C. G. Pringle, of Charlotte, Vt., has been selected by Prof. Sargent, of Harvard University, to make a tour for botanical explora tion and collection during the next on or two years through New Mexico, Arizona, California, Oregon, etc. In ad dition to work in the forestry department of the census, in which Mr. Prinrle bas been engaged the past year, and gle bas ben engaged the past year, and ing state of certain critical genera of plants, $\mathrm{Mr}$. Pringle is to superintend

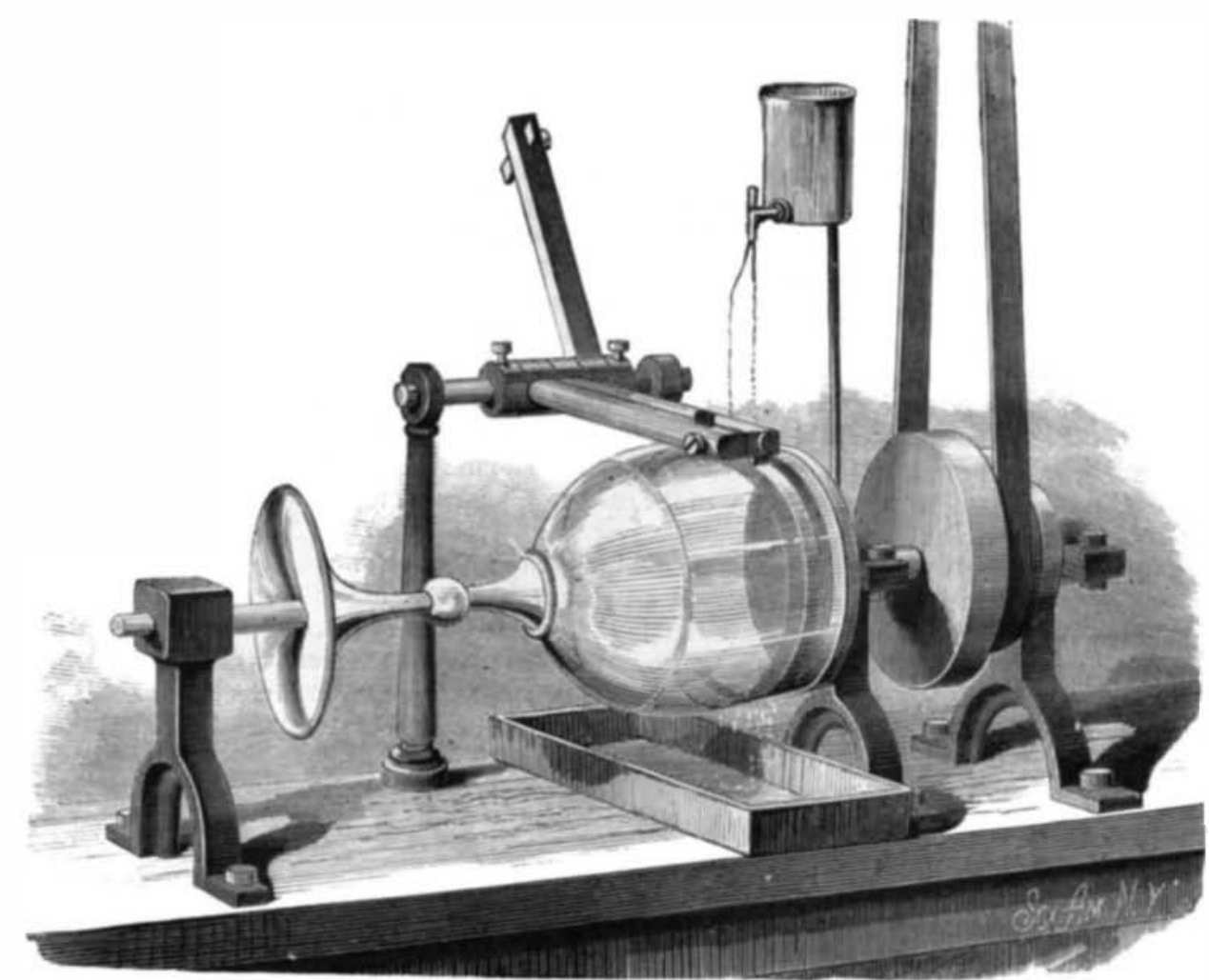

MACHINE FOR GRINDING BANDS ON GOBLETS

Fix. 3 illustrates the effect of a lateal blow on the rim of a fly-wheel. Of course the effect is much exaggerated in the flexible wheel, but it shows the form taken by the rim under a blow, the blnw producing a much greater effect on the whicel while in motion than when at rest.

\title{
NEW INVENTIONS.
}

An improvenent in the manufacture of embroidery has been patented by Mr. John Wiget, of Arbon, Switzerland. The object of this invention is to embroider eyelets, spiders, sprigs, dots, or any other figures in such a manner that the figures shall be connected together only by embroidery thread.

Mr. Daniel Aubert, of Sainte Croix, Switzerland, has patented an improved musical box. This invention relates to mechanism for musical boxes $10 \mathrm{in}$. crease the time of working, and admit of their being placed in a clock case in connection with a clock, for example, only to be wound up every eight days. at the same time as the clock is wound An improved rotary registering mea ure for linear measurements has been patented by Mr. Lewis W. Brown, of Osage City, Kan. The invention con sists of a circular case or frame containing a unit and a tens wheel of equal History, New York, of specimens (including trunk sections, or frequently and regularly, tends to turn laterally on an lorlding between them a pinion, which is attachcd to the flowers, lcaves, fruits, etc., as well as the principal commer axis between that of the normal rotation and that of the handle of the device, and of a larger circumfercntially toothed cial and economic products of each) of the more important extraneous disturbing force. This tendency exists in wheel secured upon the hub of the unit wheel that they may species of trees found in the regions which he is to visit. ordinary wheels, although not visible. The engraving revolve together, so that as the device is moved over the face Mr. James Kelly isto accompany him as principal assistant. shows a flexible wheel, which clearly exhibits the effects of an object the larger wheel is made to revolve and turn the

\section{BURSTING OF FLY-WHEELS}

The theory of the bursting of fly-wheels, which has been accepted in the majority of cases, is that the centrifugal force due to a high velocity overcomes the cohesive force of the particles of the material of which the wheel is com-
posed. of of these disturbing forces. The rim is of rubber, the unit wheel once in each revolution, whilile at each revolution spokes of spring wire, and when the whcel is revolved the unit wheel causes the tens wheel to move through a tenth very rapidly and moved in a plane parallel with its plane of
rotation, no di turbance results, and no effect is produced by
revolve, firures that indicate the measurements of the object moving it at right angles to its plane of rotation; but when over which they have been mover.

he wheel is turned even slightly on an axis at right angles Mr. George W. Henley, of Jackson, Mo., has patented an to its geometrical axis by swinging the shaft laterally, the improved horse detacher. The invention consists of im, while preserving its circular form, inclines to the plane forward curved stud inserted in each end of a singletree to Of course this explanation is entirely inadequate when of the rotation of its shaft, bending the spokes into a con- receive the rear ends of the traces, of springs secured on the applied to : wheel whose strength is sufficient to resist any cave furm on one side of the hul and convex on the other, face of a singletree and bending down in contact witb the tendency to fly to pieces from purely centrifugal action un ler the conditions of its use but of the fact that such wheels bur'st no evidence i needed, and some cause other than centrifugal force must be assigned for the bursting. Supposing the fly-wheel to be perfectly balanced and witbout defects in material or design, it may be driven without danger at any velocity out danger at any velocity usually coridered within the limit of safety, so long as it continues to rotate in a plan at right angles to its geo. metrical axis. And it may be moved in the plane of its rotation or at right angles to it, that is, in the direction of the length of the shaft, without creating any more inter nal disturbance than would rult from moving it in result from move it in the same way while at rest. But when a force tending to produce rotation at right angles to the plane of the wheel's rotation is applied, the effect will be vastly different, and the result will be a tendency to rotate about a new axis

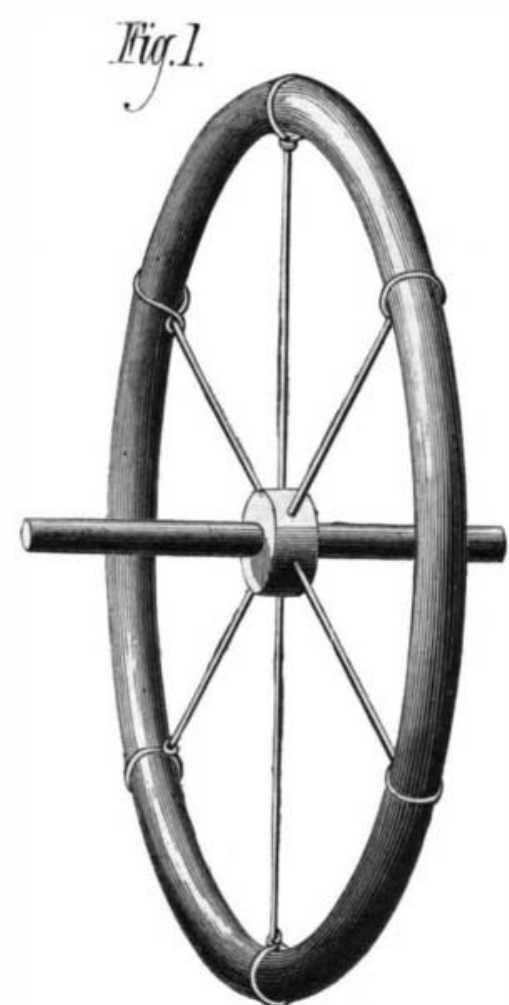

Fire.?.

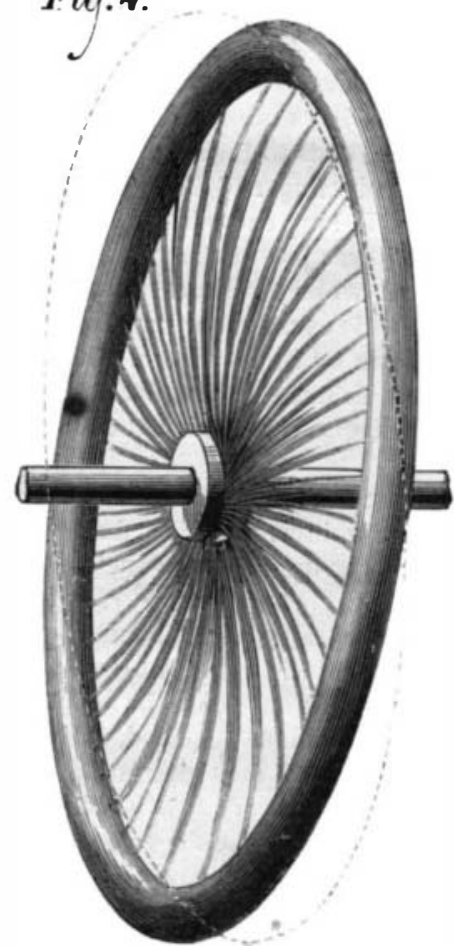

FLEXIBLE FLY-WHEEL. from accidentally slipping from accidentally slipping necting the springs, by which the springs are raised from the studs so that the traces may become disengaged.

An improved mosquito.ne ting frame for bedsteads, whlich is simple, light, durable, and convenient, has bee patented by Mr. Alfred $\mathrm{H}$. Bailey, of Palestine, Texas. The invention consist of mosquito netting frame formed of two longitudinal rods fastened to uprights at tached to the bedposts, and held by cords or wires pas ing from the outer ends of each of the rods to the top of each upright.

An improved toy pistol which is to contain a cortai quantity of ammunition fed every time the triger pulled thus permithing pulled, thus permiltiog repeate fining without reloading, has been patented by Mr. Henry Klassert, of Buffalo, N. Y. The invention consists of a pistol fram
with a removable side, i

between the other two, and the centrifugal strain upon the showing the effects of the disturbing force on the figure of which frame the trigrer and hammer are mounted on ile portant and sets up lateral vibrations and wave motions in the rim

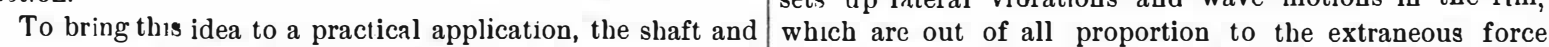
ty $y$ wheel of a high speed engine may be taken as ac exam- applied. ple Let the wheel be correctly designed, well made, and From this experiment it is evident that the lateral swing- for opening, closing, and locking blinds and shutters, ha well balanced, and if its shaft is properly lined and sup- ing of the shaft of a fly-wheel (for instance when its jour- been patented by Mr. Joseph S. O'Brien, of North Wilbra ported in rigid journal boxes, the wheel will perform its nal boxes are loose, or when the frame of the machine of ham, Mass. It consists of the combination of an improve office without danger of bursting; but support the same which the fly-wheel forms a part is yielding) tends to weak- spring hinge for throwing the blind out of a locked position, wheel and shaft upon weak plummer blocks, and allow one en the wheel even when the lateral movement is slight; and a spring catch, and attached cord for pulling the blind fully or both of its journals to move Jaterally at every stroke of where it is great, as when the shaft is broken, the twisting open or closed, and locking it in both positions. 